\title{
Article \\ Examination of the Quality of Particulate and Filtered Mandibular Bone Chips for Oral Implants: An In Vitro Study
}

\author{
Patrick Babczyk ${ }^{1,+}{ }^{+}$, Martin Winter ${ }^{2,+}$, Claudia Kleinfeld $^{1}{ }^{1}$, Andreas Pansky ${ }^{1}$, Christina Oligschleger $^{1}$ \\ and Edda Tobiasch ${ }^{1, *}$ \\ 1 Department of Natural Sciences, University of Applied Sciences Bonn-Rhine-Sieg, Von-Liebig-Strasse 20, \\ 53359 Rheinbach, Germany; patrick.babczyk@h-brs.de (P.B.); Claudia.Kleinfeld@h-brs.de (C.K.); \\ andreas.pansky@h-brs.de (A.P.); Christina.Oligschleger@h-brs.de (C.O.) \\ 2 Oral Surgical Practice, Martinstrasse 26-28, 53359 Rheinbach, Germany; m.j.c.winter@t-online.de \\ * Correspondence: edda.tobiasch@h-brs.de; Tel.:+49-2241-865-576 \\ + These authors contributed equally to this study.
}

check for updates

Citation: Babczyk, P.; Winter, M.; Kleinfeld, C.; Pansky, A.; Oligschleger, C.; Tobiasch, E. Examination of the Quality of Particulate and Filtered Mandibular Bone Chips for Oral Implants: An In Vitro Study. Appl. Sci. 2022, 12, 2031. https://doi.org/ 10.3390/app12042031

Academic Editors: Andrada Soanca and Alexandra Roman

Received: 28 December 2021

Accepted: 11 February 2022

Published: 16 February 2022

Publisher's Note: MDPI stays neutral with regard to jurisdictional claims in published maps and institutional affiliations.

Copyright: (c) 2022 by the authors. Licensee MDPI, Basel, Switzerland. This article is an open access article distributed under the terms and conditions of the Creative Commons Attribution (CC BY) license (https:// creativecommons.org/licenses/by/ $4.0 /)$.

\begin{abstract}
Background: Autologous bone is supposed to contain vital cells that might improve the osseointegration of dental implants. The aim of this study was to investigate particulate and filtered bone chips collected during oral surgery intervention with respect to their osteogenic potential and the extent of microbial contamination to evaluate its usefulness for jawbone reconstruction prior to implant placement. (2) Methods: Cortical and cortical-cancellous bone chip samples of 84 patients were collected. The stem cell character of outgrowing cells was characterized by expression of CD73, CD90 and CD105, followed by osteogenic differentiation. The degree of bacterial contamination was determined by Gram staining, catalase and oxidase tests and tests to evaluate the genera of the found bacteria (3) Results: Pre-surgical antibiotic treatment of the patients significantly increased viability of the collected bone chip cells. No significant difference in plasticity was observed between cells isolated from the cortical and cortical-cancellous bone chip samples. Thus, both types of bone tissue can be used for jawbone reconstruction. The osteogenic differentiation was independent of the quantity and quality of the detected microorganisms, which comprise the most common bacteria in the oral cavity. (4) Discussion: This study shows that the quality of bone chip-derived stem cells is independent of the donor site and the extent of present common microorganisms, highlighting autologous bone tissue, assessable without additional surgical intervention for the patient, as a useful material for dental implantology.
\end{abstract}

Keywords: autologous bone graft; dental implant; microbial contamination; antibiotic prophylaxis; mesenchymal stem cells; cell viability; osteogenic potential

\section{Introduction}

A sufficient vertical and transversal bone level is necessary for long-term success of endosseous dental implants [1]. Autologous bone graft is the preferred material for reconstructing jawbone defects as it contains osteoinductive and -conductive properties and does not evoke immunological reactions as must be expected from allogeneic material [2,3]. Next to natural occurring materials, artificial substances can be used for guided bone tissue engineering $[4,5]$. However, among other problems, their osteoinductive and -conductive properties are poor. Bone particles are commonly obtained from intra-oral sources such as the mandibular symphysis or the retromolar region and can be applied for the grafting procedure. Compared to extra-oral donor sites (e.g., the iliac crest, the tibia, or the skull), these donor site materials are reported to entail a reduced operating and hospitalization time as well as a better incorporation into alveolar defects with less resorption [6-8]. These bone chips and their respective cells can also be used together with spacers in guided bone regeneration. The collection of particulate bone chips during oral surgical treatment can be performed without additional donor site morbidity $[9,10]$, as the material can be easily 
obtained by bone collection traps integrated in the dental suction pipe or with special bone scrapers [11].

The osteogenic capacity of different stem cell sources is well established (Figure 1). Several stem cell types e.g., bone marrow-derived stem cells (BMSC) or umbilical vein stem cells (UVMSC) display osteogenic capacity and can be obtained in banking ready to use [12]. But also dental pulp stem cells (DPSC), periodontal ligament stem cells, and dental follicle stem cells (DFSC) can differentiate towards osteoblasts in vitro and are reported to be superior for treatment of bone defects in vivo than bone marrow-derived stem cells (BMSC) or adipose tissue-derived stem cells (ADSC) [13-16], because the cellular origin plays an important role in their osteogenic capacity. Cells isolated from the head region e.g., mandibular stem cells differentiate towards osteoblasts in vitro and contribute to wound healing in animal models more efficiently than cells from other body regions e.g., tibia or femur [17-22]. Cells from hard tissues, especially from the head region, seem to be already pre-committed towards the osteogenic lineage, displaying less unwanted differentiation effects.
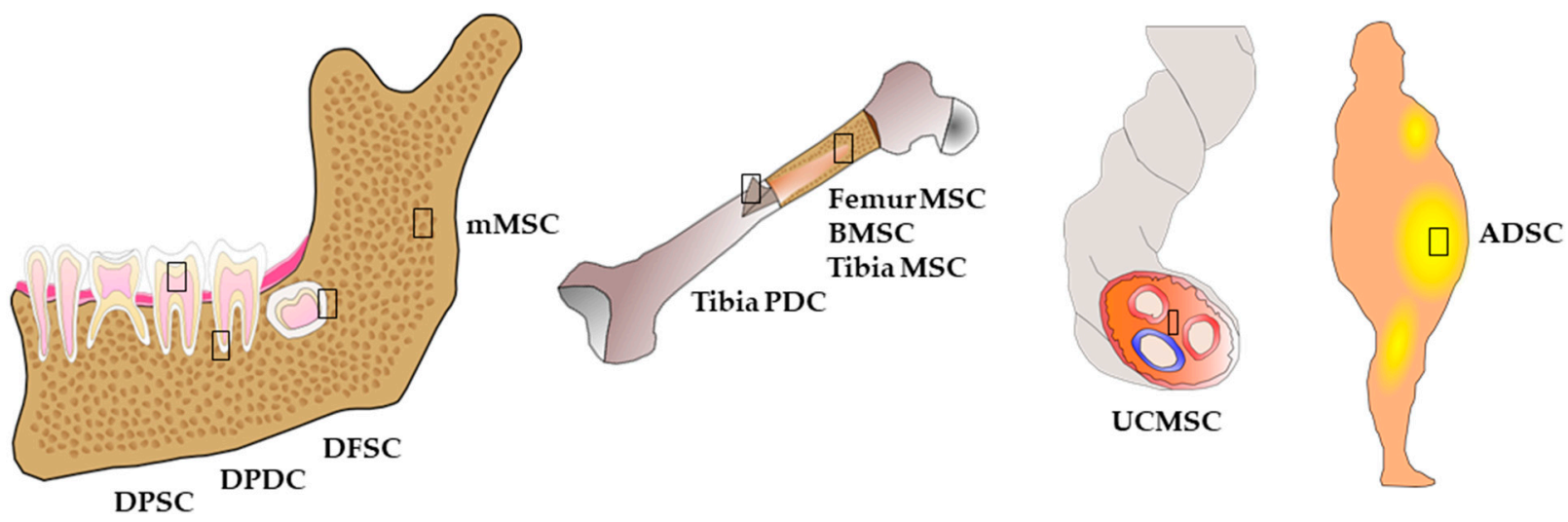

\section{steogenic Capacity}

Figure 1. Osteogenic capacity of different stem cell types. Different stem cell types have been shown to be pre-committed towards the osteogenic lineage depending on their origin. Cells isolated from hard tissues e.g., teeth and bone show a higher osteogenic capacity than cells isolated from adipose tissue. The cells isolated from bones of the head region seem to be more capable of osteogenic differentiation than cells isolated from other bone regions. DPSC: dental pulp stem cells; DPDC: dental periosteumderived cells; DFSC: dental follicle stem cells; (m) MSC: (mandibular) mesenchymal stem cells; PDC: periosteum-derived cells; BMSC: bone marrow stem cells; UCMSC: umbilical cord stem cells; ADSC: adipose tissue-derived stem cells.

However, the quality of bone grafting materials form the oral cavity is insufficiently investigated and has been evaluated inconsistently in the literature. Especially microbial contamination of the collected bone tissue is a matter of concern, since it might lead to postoperative complications or failure of the implantation process [23,24]. Pre-surgical antibiotic treatment and chlorhexidine rinse seems to significantly decreases the bacterial load [25-28]. Nevertheless, it is still unclear whether antibiotic prophylaxis is beneficial and which antibiotic is most effective [29-33]. Conflicting data also exists regarding the viability of the collected bone particles. Several studies identified an osteogenic differentiation potential of cells growing out of bone chips [34-37]. Where as bone debris was identified as not ideal grafting material, since its viability could not be demonstrated consistently in another study [38].

The aim of this study was to systematically investigate in more detail the quality of particulate and filtered bone particles and their potential use as bone grafts in regenerative dentistry with and without antibiotic pretreatment. The outgrowth probability of stem 
cells from freshly isolated bone chips was determined with respect to the pretreatment and the osteogenic differentiation potential was evaluated by specific osteogenic marker expression. Further the microbiological contamination was determined by oxygen requirements, gram staining, catalase tests, oxidase tests and the presence of anaerobic bacteria, and genera of contaminating streptococci or staphylococci were classified to pinpoint on which contaminants might or might not influence the quality of the bone chip material.

\section{Materials and Methods}

\subsection{Patient Groups}

Eighty-four patients ( 49 women and 35 men, mean 39.2 years old, range 14-81 years) were included in this study. The patients were divided into four groups based on the bone chip donor site and presurgical antibiotic treatment: cortical bone chips with antibiotic pretreatment (antibiotic pretreatment is not recommended in the treatment plan for wisdom tooth removal in Germany), cortical bone chips without antibiotic pretreatment, corticalcancellous bone chips with antibiotic pretreatment and cortical-cancellous bone chips without antibiotic pretreatment. Patients with general good health status (no systemic diseases) were included. Pregnant women and patients allergic to Clindamycin were excluded. Patients with systemic diseases and drug treatments, such as anti-rheumatic drugs, cortisone therapy, or known high blood pressure medication were also excluded from study participation. In a single-blinded experimental setup the patients were randomly assigned to the four treatment groups and anonymized preventing experimental bias. The dental surgeon randomized and anonymized samples (labeled as $\mathrm{K}+$ number), which were handed over to the scientists for subsequent analysis. After the experiments were finalized, the results were distributed in the respective four groups with the help of the surgeon.

The study protocol was accepted by the Ethics Committee of the University of Bonn (reference number 209/04). All patients gave their informed consent before taking part in the study.

\subsection{Surgical Procedure}

Samples of the mandible were collected from patients during wisdom tooth removal (cortical bone chip group) or implant insertion (cortical-cancellous bone chip group), with or without antibiotic pretreatment of the patients $(300 \mathrm{mg}$ Clindamycin ten and two hours before surgery). All wisdom teeth isolated were completely impacted in the jawbone before surgery.

Prior to surgery, all patients rinsed with $20 \mathrm{~mL}$ of $0.2 \%$ chlorhexidine solution (Chlorhexamed $^{\circledR}$ Forte) for $60 \mathrm{~s}$.

Cortical bone chips were obtained by ablation of the cortical bone using single use round drills (HP 10 ISO No. 500104001001 027, Beavers Dental, Morrisburg, ON, Canada) at a speed of 1000 revolutions per minute. For preparation of the implant bed, the single use drill kit (Disposable Drill Kit DDKN315, Biomet 3i, Palm Beach Gardens, FL, USA) was used by maximum 1000 revolutions per minute (Figure 2). The surgical drills were cooled with sterile physiological saline solution.

All bone chip samples were collected by the same team (surgeon/assistants) under conservation of a stringent aspiration protocol (two separate suction tips) according to Haessler and coworkers and by using a single bone filter (BoneTrap ${ }^{\circledR}$, Astra Tech, Mölndal, Sweden) $[39,40]$. The bone chips were transferred immediately into cold sodium chloride solution $(0.9 \% w / v)$ and kept cooled until processing for subsequent cell culture and microbiological evaluation. 

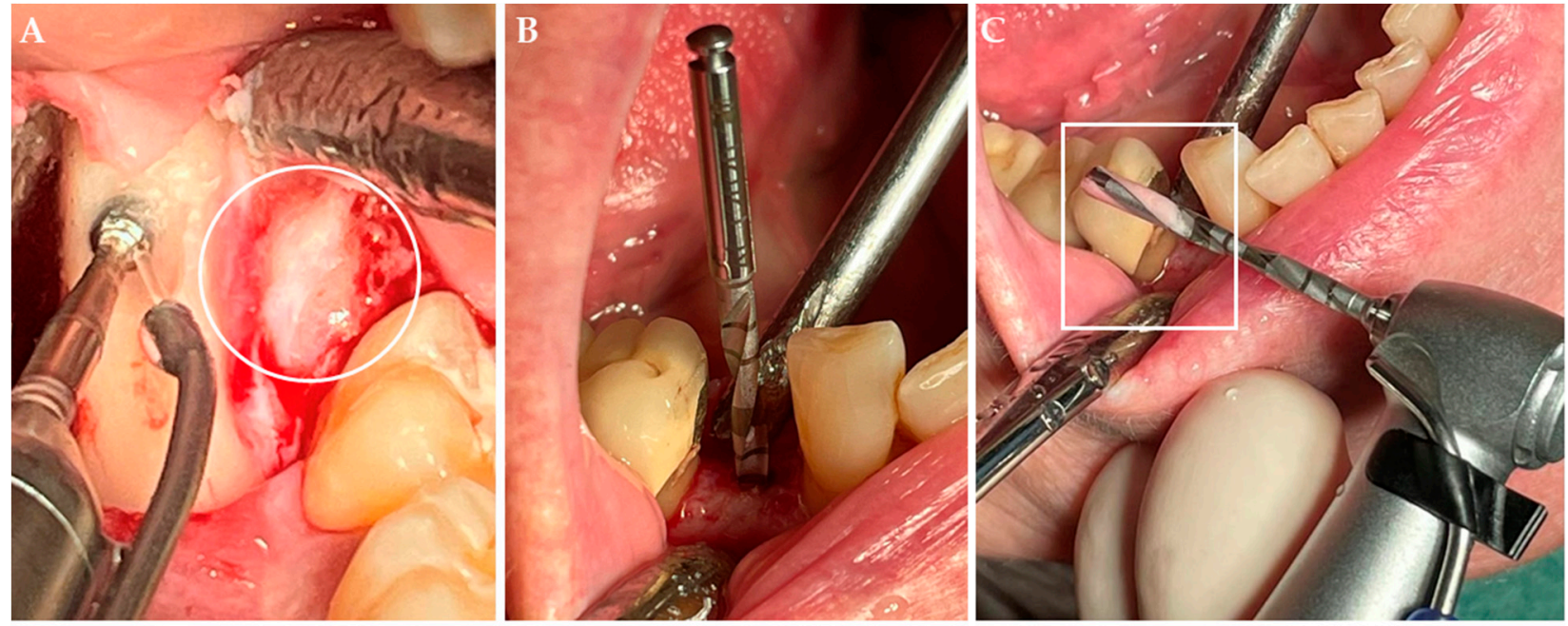

Figure 2. Collection of bone chips. (A) Collection of cortical bone chips during wisdom tooth removal. The wisdom tooth (circle) within the dental follicle is visible next to the round drill. (B) Collection of cortical-cancellous bone chips during implant insertion with a drill kit. (C) Within the groove of the drill the bone chips can be found (rectangle). The bone chips were aspirated and collected in a bone traps.

\subsection{Sample Size Measurement}

The collected samples were centrifuged for $1 \mathrm{~min}$ at $500 \times g$. Afterwards the supernatant was carefully aspirated and the resulting pellet was transferred to $1.5 \mathrm{~mL}$ tubes. $100 \mu \mathrm{L}$ of the supernatant was used for further microbiological investigations. Subsequently, the weight and the volume of the pelleted samples were determined before dissection. Of the obtained bone material $100 \mathrm{mg}$ each was used for cell culture and additional microbiological analysis.

\subsection{Cell Culture}

\subsubsection{Isolation of Bone Chip-Derived Stem Cells (BDSCs)}

For cell isolation, bone chips were washed with phosphate buffered saline (PBS). The material was distributed homogenously in a cell culture dish and stem cell medium (SCM) was added. The SCM consisted of Dulbecco's modified Eagle's medium (DMEM) supplemented with $10 \%$ fetal calf serum (FCS), 2 mM L-alanyl-L-glutamine, 100 units $/ \mathrm{mL}$ penicillin, $100 \mu \mathrm{g} / \mathrm{mL}$ streptomycin and $1 \%$ amphotericin. The bone chips were cultured at $37^{\circ} \mathrm{C}$ in humidified atmosphere with $5 \% \mathrm{CO}_{2}$ until first outgrowing cells were visible. The bone chips were then removed by washing with PBS. SCM was added and the plastic adherent cell fraction was cultured until $80 \%$ confluence for further use.

\subsubsection{In Vitro Osteogenic Differentiation}

For in vitro osteogenic differentiation, the BDSCs were seeded at a density of $1.3 \times 10^{3}$ cells $/ \mathrm{cm}^{2}$. After $24 \mathrm{~h} \mathrm{SCM}$ medium was replaced with osteogenic medium (OM) consisting of SCM supplemented with $0.1 \mu \mathrm{M}$ dexamethasone, $10 \mathrm{mM} \beta$-glycerol phosphate and $50 \mu \mathrm{M}$ ascorbic acid. The OM medium was changed once per week. For negative control BDSCs were cultured with non-supplemented SCM. After 28 days, extracellular matrix mineralization was visualized by Alizarin Red S staining. Briefly, cells were fixed with $4 \%$ formaldehyde and stained with $40 \mathrm{mM}$ Alizarin Red S (pH 4.3). In addition, gene expression of the osteogenic markers osteonectin $(\mathrm{ON})$ and bone morphogenetic protein 2 (BMP-2) was analyzed by RT-PCR. The human osteosarcoma cell line SaOS-2 (DSMZ number: ACC 243) was used as positive control (data not shown). 


\subsubsection{Semiquantitative RT-PCR}

RNA was extracted with TRI Reagent ${ }^{\mathrm{TM}}$ (Sigma-Aldrich Chemie GmbH, Munich, Germany) and reverse transcribed into cDNA using Revert Aid Reverse Transcriptase (Thermo Fischer, Frankfurt, Germany) and oligo-dT primer (Metabion, Planegg, Germany). Gene expression for CD73, CD90, CD105, BMP-2 and B-Actin was used following primer sets:CD73 (5': AGG GCA CYA TCT GGT TCA CCG T, 3': AGG AAT GCT GCT GTT KAG AAG AAT GG), CD90 (5': TCC CGA GGG CAG AAG GTG ACC, 3': GGC RTG GAG GAG GGA GAG GGA), CD105 (5': CCT CTT CCT CAT CTG CAT CAG CG, 3': GGC AGG AAG CAG AGG GCG AAG AC), ON (5': TGT GGG AGC TAA TCC TGT CC, $3^{\prime}$ : TCA GGA CGT TCT TGA GCC AGT), BMP-2 (5': AGC AGG TCT TTG CAC CAA GAT G, 3': CCC TCC ACA ACC ATG TCC TGA), $\beta$-actin (5': GCC ATC CTG CGT CTG GAC CTG G, 3': TAC TCC TGC TTG CTG ATC CAC A). Expression was evaluated semi-quantitative by densitometry of bands.

\subsection{Microbiological Analysis}

For the determination of microbial contaminations, the bone chip samples were rolled over the surface of Columbia blood agar (CBA) and fastidious anaerobe agar (FAA) plates (Oxoid, Wesel, Germany, respectively according to QUELAB, Montréal, QC, Canada). Additionally, the transport solution was plated onto CBA and FAA plates. Plates were incubated under aerobic and anaerobic conditions overnight at $37^{\circ} \mathrm{C}$. For the incubation under anaerobic conditions, the GasPak ${ }^{\mathrm{TM}} 100$ system (BD Diagnostics, Heidelberg, Germany) was used. With regard to morphological differences, single colonies were picked, isolated and characterized by Gram staining, catalase and oxidase tests. For the detection of anaerob bacteria, streptococci and staphylococci, single colonies were further characterized for metabolic features, using three different API ${ }^{\circledR}$ stripes (Biomérieux, Nuertingen, Germany) according to manufactures' instruction.

\subsection{Statistical Analysis}

The patient data, which are subjected to statistical analysis, include information on the treatment procedure (with and without antibiotic pre-treatment) and type of bone tissue (cortical/cortical-cancellous). Furthermore, information is available on outgrowth of the cells and the duration of outgrowth, and results with regard to contaminations of the samples. Age and sex of the patients is known. The data of the patients were subdivided into four groups according to the criteria type of bone tissue (cortical/corticalcancellous) and type of treatment (with/without antibiotic pre-treatment), respectively. In our analysis we focus on the probability of outgrowth success and the respective duration of the associated outgrowth of the cells as a function of the different groups. The statistical parameters (mean, standard deviation SD and standard error of the mean SEM) for the successful outgrowth of the cells and the duration of the outgrowth are determined and the results are statistically compared between the different groups. The statistical comparison of the means aims to examine whether the mean values differ significantly or not. The hypothesis tests to check for equality of the means are carried out with a significance level $p$. Unless otherwise stated, $p$ values $<0.05$ were considered statistically significant.

Hypothesis tests comparing two mean values are based on $t$-tests. Since the patient data were divided into four groups, statistical analysis using $t$-tests is not applicable. Therefore, at the beginning of the statistical analysis, $F$-tests were performed to check the four groups for homogeneity of variance, which is a prerequisite for using one-way analysis of variance (ANOVA) (ORIGIN 8.1 Software, OriginLab Corporation, Northampton, MA, USA). ANOVA is applied to assess mean values between (three and more) groups. In detail, the applied ANOVA analysis is based on the methods according to Bonferroni (pairwise comparisons of mean values; group sizes must not be equal), Scheffe (differences of means are compared, i.e., four values are considered; group sizes must not be equal) and Turkey (pairwise comparisons of means; group sizes are equal). Mean values of the duration 
of outgrowth differs significantly, if at least one mean value differs significantly; i.e., the means of statistical totalities are considered to be significantly different.

\section{Results}

\subsection{Outgrowth Statistics}

In total 84 bone chip samples (49 from women and 35 from men) were collected., The average mass of the samples was $0.25 \mathrm{~g}$ for cortical-cancellous bone chips (volume $240 \mu \mathrm{L}$ ) and $0.45 \mathrm{~g}$ for cortical bone chips (volume $420 \mu \mathrm{L}$ ). In 65 samples outgrowing cells could be observed ( 39 from women and 26 from men). The mean age of the patients was $39.2 \pm 23.2$ years (Table 1 ).

Table 1. Patient Groups.

\begin{tabular}{ccccc}
\hline Patient Group & $\begin{array}{c}\text { Number of } \\
\text { Samples }\end{array}$ & Mean Age & Female & Male \\
\hline $\begin{array}{c}\text { Cortical w/antibiotic pretreatment } \\
\text { Cortical w/o antibiotic } \\
\text { pretreatment }\end{array}$ & 15 & $22.2 \pm 13.3$ & 7 & 8 \\
$\begin{array}{c}\text { Cortical-cancellous w/antibiotic } \\
\text { pretreatment }\end{array}$ & 30 & $19.4 \pm 5.5$ & 20 & 10 \\
$\begin{array}{c}\text { Cortical-cancellous w/o antibiotic } \\
\text { pretreatment }\end{array}$ & 19 & $61.7 \pm 11.8$ & 12 & 8 \\
\hline Total & 84 & $39.2 \pm 23.2$ & 49 & 35 \\
\hline
\end{tabular}

Values for the patient age are mean $\pm \mathrm{SD} ; \mathrm{w} /$, with; w/o, without.

The data was divided into four groups: cortical bone chips with antibiotic pretreatment, cortical bone chips without antibiotic pretreatment, cortical-cancellous bone chips with antibiotic pre-treatment and cortical-cancellous bone chips without antibiotic pre-treatment. Table 2 summarizes the outgrowth success for the collected bone chips, which did not differ between patient groups. However, the mean outgrowth time of the cortical-cancellous bone chips without antibiotic pretreatment was significantly different from the other groups $(p<0.02)$. Cells derived from cortical-cancellous bone chips without antibiotic pretreatment of patients needed significantly less time for outgrowth compared to cortical bone chips with or without antibiotic pretreatment and cortical-cancellous bone chips with antibiotic pretreatment $(7.00 \pm 2.18$ compared to $12.85 \pm 3.24,15.81 \pm 5.32$ and $13.47 \pm 5.25$ days, respectively).

After evaluation of the data according to the sample characteristics: cortical, corticalcancellous, with or without antibiotic pretreatment, the corresponding outgrowth was calculated (Table 3). The patients' bone chip samples had an overall outgrowth probability of $77.38 \%$. Statistical analysis confirmed that the cortical-cancellous bone chips group with and without antibiotic pretreatment had slightly higher outgrowth probabilities than the cortical bone chips group with and without antibiotic pretreatment $(79.49 \%$ vs. $75.56 \%)$. The highest outgrowth success was found in the cortical and cortical-cancellous bone chips group with antibiotic pretreatment which was significantly higher $(p<0.05)$ compared to the cortical and cortical-cancellous bone chips group without antibiotic pretreatment ( $85.71 \%$ compared to $71.43 \%$ ). To illustrate the outgrowth probability related to antibiotic pretreatment, the groups were restructured and shown in Table 3. 
Table 2. Outgrowth probability and time of the bone chip samples with respect to the patient group.

\begin{tabular}{|c|c|c|c|c|c|}
\hline Patient Group & $\begin{array}{l}\text { Number of } \\
\text { Samples }\end{array}$ & $\begin{array}{l}\text { Outgrown } \\
\text { Samples }\end{array}$ & $\begin{array}{l}\text { Outgrowth } \\
\text { Time [days] }\end{array}$ & SEM & $\begin{array}{c}\text { Outgrowth } \\
\text { Probability } \\
{[\%]}\end{array}$ \\
\hline Cortical w/antibiotic pretreatment & 15 & 13 & $12.85 \pm 3.24$ & 0.90 & 86.67 \\
\hline Cortical w/o antibiotic pre-treatment & 30 & 21 & $15.81 \pm 5.32$ & 1.16 & 70.00 \\
\hline $\begin{array}{l}\text { Cortical-cancellous w/antibiotic } \\
\text { pretreatment }\end{array}$ & 20 & 17 & $13.47 \pm 5.25$ & 1.27 & 85.00 \\
\hline $\begin{array}{l}\text { Cortical-cancellous } \mathrm{w} / \mathrm{o} \text { antibiotic } \\
\text { pretreatment }\end{array}$ & 19 & 14 & $7.00 \pm 2.18$ * & 0.58 & 73.68 \\
\hline
\end{tabular}

Values for the outgrowth time are mean $\pm \mathrm{SD} ; \mathrm{w} /$, with; w/o, without. ${ }^{*}$ significantly lower outgrowth time $(p<$ 0.02) compared to the other groups.

Table 3. Outgrowth probability of the bone chip samples after regrouping of the patient groups.

\begin{tabular}{lccc}
\hline \multicolumn{1}{c}{ Patient Group } & Number of Samples & Outgrown Samples & $\begin{array}{c}\text { Outgrowth } \\
\text { Probability [\%] }\end{array}$ \\
\hline Cortical w/\& w/o antibiotic pretreatment & 45 & 34 & 75.56 \\
Cortical-cancellous w/\& w/o antibiotic pretreatment & 39 & 31 & 79.49 \\
Cortical and cortical-cancellous w/antibiotic pretreatment & 35 & 30 & $85.71^{*}$ \\
Cortical and cortical-cancellous w/o antibiotic & 49 & 35 & 71.43 \\
pretreatment & & & \\
\hline
\end{tabular}
w/, with; w/o, without. * significan
group w/o antibiotic pre-treatment.

\subsection{Characterization of Bone Chip-Derived Stem Cells (BDSCs) \\ 3.2.1. Confirmation of the BDSC Stem Cell Character}

The cells growing out of the collected bone chip samples adhered to plastic and showed typical spindle-shaped stem cell morphology (Figure 3d). BDSCs were tested for three standard stem cell markers in accordance with the minimal criteria proposed by the International Society for Cellular Therapy [41]. The cells positively expressed the marker genes CD73, CD90 and CD105 with varying degrees shown by RT-PCR (Figure 3e), confirming their stem cell character.

\subsubsection{In Vitro Osteogenic Differentiation}

Osteogenic induction of BDSCs of all four patient groups was successful with minor variations in the strength of differentiation (Figure 4). After 4 weeks of osteogenic differentiation typical calcium mineralization could be visualized in all 4 groups using Alizarin Red S staining (Figure 4a). In addition, the osteogenic induced BDSCs showed increased gene expression of the osteogenic markers osteonectin and BMP-2 (Figure $4 \mathrm{~b}$ ). The patients age, collection site and pretreatment (cortical vs. cortical-cancellous bone chips with or without antibiotic pre-treatment) had no effect on the osteogenic differentiation potential of the BDSCs.

\subsection{Microbiological Analysis}

\subsubsection{Distribution of Gram Staining Forms and Morphology}

Bone chip samples from all four groups contained viable microorganisms, even after Clindamycin pretreatment (Figure 5). In total 259 morphologically different microorganisms were observed. The bacterial species predominantly found belonged to the families of Streptococcaceae and Staphylococcaceae (95.7\%). Rod-shaped microorganisms were found in lower percentage (3.9\%). Yeast could only be isolated from one bone chip sample $(0.4 \%)$. 

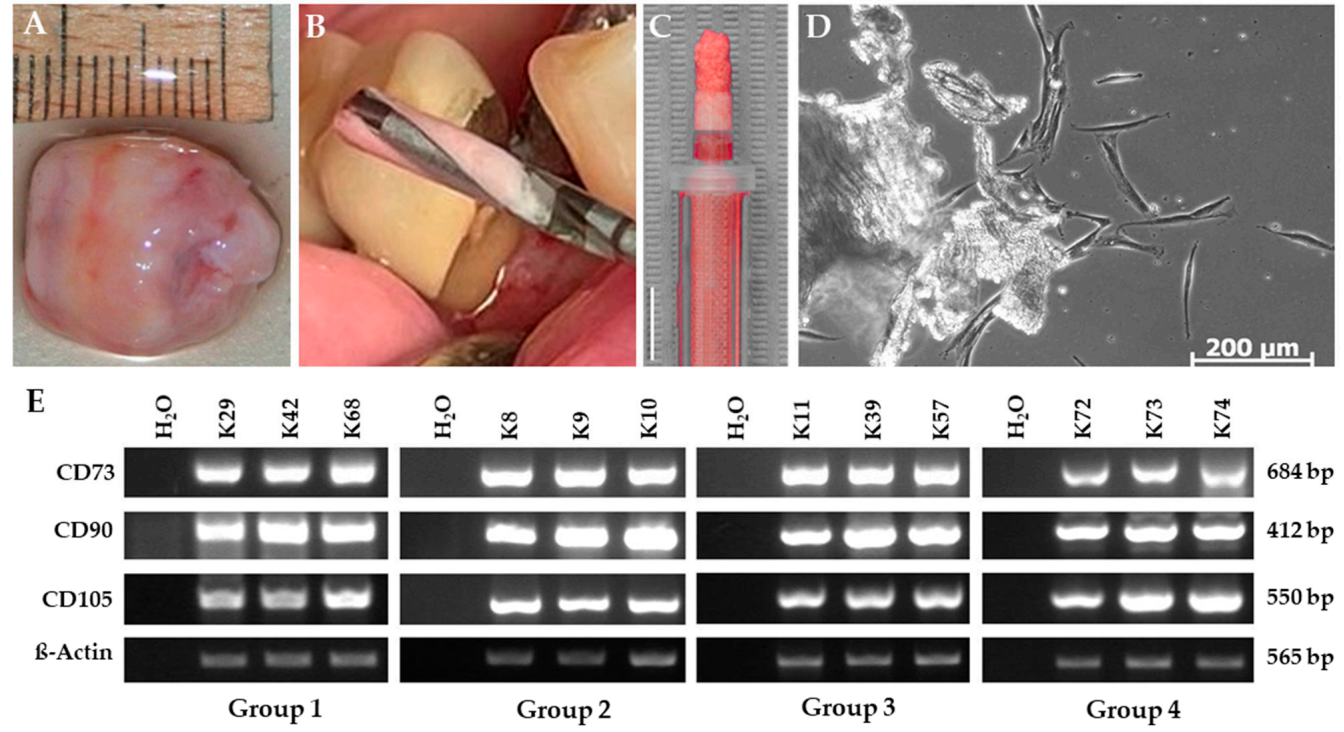

Figure 3. Characterization of bone chip-derived stem cells (BDSCs). (A) Isolated dental follicle (B) Bone material in grooves of the drill. (C) Particulate jawbone material in a syringe. Size bar equals $5 \mathrm{~mm}$. (D) Cells proliferating out of the bone chip material. (E) RT-PCR for the mesenchymal stem cell markers CD73, CD90, and CD105 in BDSCs for the patient groups: cortical bone chips with antibiotic pre-treatment (group I), cortical bone chips without antibiotic pre-treatment (group II), cortical-cancellous bone chips with antibiotic pre-treatment (group III) and cortical-cancellous bone chips without antibiotic pre-treatment (group IV) as indicated. $\beta$-Actin served as internal expression control, $\mathrm{H}_{2} \mathrm{O}$ served as negative control. The pictures shown are representative for outgrown bone chip samples of the respective group.

A

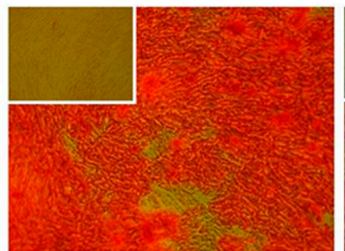

Group 1

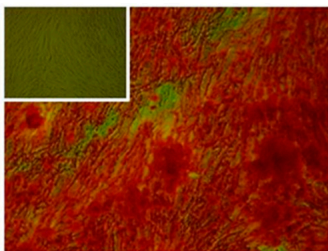

Group 2

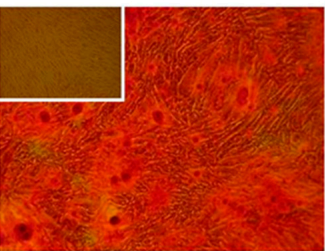

Group 3

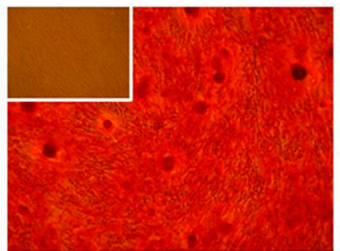

Group 4

B

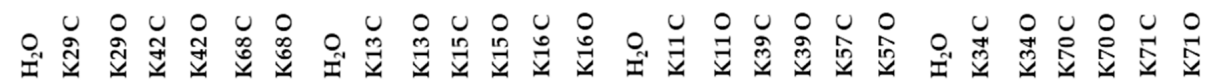

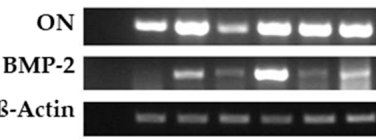

Group 1
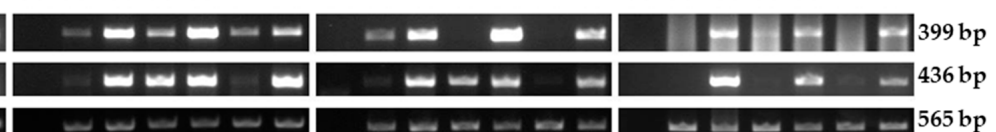

Group 2

Group 3

Group 4

Figure 4. In vitro osteogenic differentiation. (A) Alizarin Red S staining after 28 days in vitro osteogenic differentiation of BDSCs for the patient groups cortical bone chips with antibiotic pretreatment (group I), cortical bone chips without antibiotic pre-treatment (group II), cortical-cancellous bone chips with antibiotic pre-treatment (group III) and cortical-cancellous bone chips without antibiotic pre-treatment (group IV) as indicated. Main frame: osteogenic induced BDSCs, insert: noninduced BDSCs served as negative control, magnification 40×. (B) RT-PCR for the osteogenic markers osteonectin (ON) and bone morphogenetic protein 2 (BMP-2) after 4 weeks osteogenic differentiation of BDSCs. $\beta$-actin served as internal control, $\mathrm{H}_{2} \mathrm{O}$ served as negative control. The pictures shown are representative for outgrown bone chip samples of the respective group. C: non-induced BDSCs, O: osteogenic induced BDSCs. 


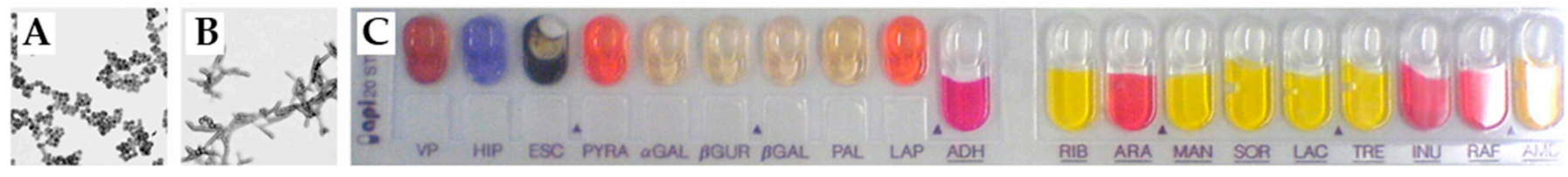

D Microorganisms in all Samples

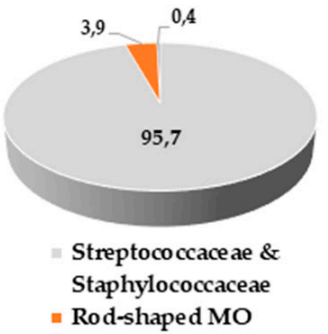

$\mathrm{E}$

Oxygen Requirements

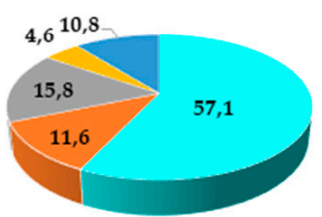

- Facultative anaerobes = Aero-tolerant

= Obligate anaerobes = Obligate aerobes

= No Growth
Bone Chips Outgrow Samples

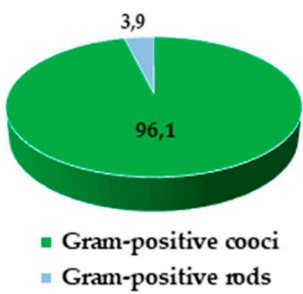

Oxygen Requirements Bone Chips Outgrow Samples

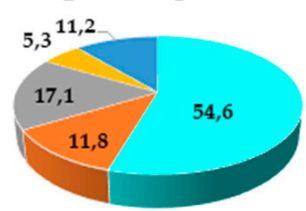

- Facultative anaerobes " Ae ro-tole rant
" Obligate anaerobes $=$ Obligate aerobes
" No Growth
Bone Chips No Outgrow Samples

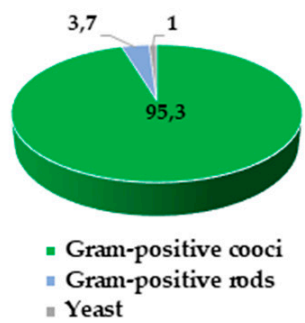

Oxygen Requirements Bone Chips No Outgrow Samples

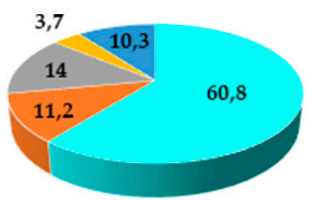

\footnotetext{
- Facultative anaerobes $=$ Aero-tole rant

= Obligate anaerobes = Obligate aerobes

= No Growth
}

Figure 5. Microbiological analysis. Microscope images of (A) streptococcaceae and (B) staphylococcaceae. (C) API ${ }^{\circledR}$ Test Strip for biochemical features of microorganisms. (D) The collected bone chip samples have been microbiological investigated for viable microorganisms and the occurrence of Gram-positive cocci, rods and yeast either in samples in which cells grew out or not. (E) Oxygen requirements for anaerob or aerob microorganisms in bone chip samples with and without cellular outgrowth (numbers represent \%).

In the bone chip samples that showed cell outgrowth, 152 different microorganism forms were detected. $96.1 \%$ of those were gram-positive cocci and 3.9\% were grampositive rods. From the bone chip samples for which no cell outgrowth could be observed, 107 diverse shaped microorganisms could be isolated. Among them $95.3 \%$ were grampositive cocci, $3.7 \%$ were gram-positive rods and 1 microorganism could be identified as yeast.

\subsubsection{Oxygen Requirements of Microorganisms}

With regard to their oxygen requirements we identified that $57.1 \%$ were facultative anaerobes, $11.6 \%$ aero-tolerant, $15.8 \%$ obligate anaerobes, $4.6 \%$ obligate aerobes and $10.8 \%$ showed no growth in the medium.

The samples for which cell outgrowth could be observed contained $54.6 \%$ facultative anaerobes, $11.8 \%$ aero-tolerant, $17.1 \%$ obligate anaerobes, $5.3 \%$ obligate aerobes; $11.2 \%$ showed no growth in the medium.

Of the 107 morphologically different microorganisms isolated from bone chip samples without cell outgrowth $60.8 \%$ were facultative anaerobes, $11.2 \%$ were aero-tolerant, $14.0 \%$ were obligate anaerobes, $3.7 \%$ were obligate aerobes and $10.3 \%$ showed no growth in the medium. We could not observe any differences for oxygen requirements between the sample groups or the antibiotic pretreatment. 


\section{Discussion}

In this study, cells derived from mandibular bone chips were evaluated. The isolated cells showed typical stem cell characteristics according to the minimal criteria for defining multipotent mesenchymal stem cells, as suggested by "The International Society for Cellular Therapy" [41]. These criteria are among others plastic adherence, spindle-shaped morphology and positive expression of the markers CD73, CD90, and CD105. The outgrown cells displayed a strong differentiation potential towards the osteogenic lineage irrespective of the patient group. Interestingly, in contrast to ATSCs, BDSCs were found to differentiate into adipocytes only to a marginal extent (data not shown). Similar results have been reported for dental follicle-derived stem cells (DFCs) [42-44]. The limited differentiation potential indicates a lower plasticity which is correlating with a higher differentiation status towards the osteogenic lineage. Therefore, BDSCs can be expected to possess lower tumorigenicity, as well as a less undifferentiated cell population, or cell differentiating into an unwanted lineage compared to stem cells from other body parts, if differentiated towards the osteoblasts. The pre-commitment towards the osteogenic lineage poses BDSCs as an ideal tool for dental bone grafting [45]. Their differentiation state can be categorized between that of mesenchymal stem cells and osteoblasts. Springer and coworkers classified cells derived from bone of the iliac crest as osteoblast-like, since they stained positive for osteocalcin and alkaline phosphatase [46]. Several other research groups identified outgrowing cells of cortical or cancellous bone as osteoblasts, but none of these studies investigated the differentiation potential towards the adipogenic lineage as evidence of an undifferentiated state or for a possible lineage commitment [33,36].

Parathyroid hormone-related protein (PTHrP) was described as a signaling molecule that affects the differentiation process of mesenchymal stem cells [47]. The differential expression levels of specific PTHrP isoforms might be considered as a molecular signature associated with the respective differentiation state of BDSCs during osteogenesis.

Our results showed differences between the outgrowth time-point of cells derived from cortical bone compared to those from cortical-cancellous bone. On average BDSCs of the cortical-cancellous bone chip group showed faster outgrowth compared to the cortical bone chip group. This is supported by similar results from the literature. Chiriac and colleagues reported outgrowth times of cortical bone-derived cells varying from 6 to 19 days, whereas cells of mixed sources were reported to grow out after 5 to 7 days $[33,36]$.

It must be noted that donors of the cortical bone chip group were on average younger than donors of the cortical-cancellous bone chip group in our study. This could be a possible confounding reason for the differences in outgrowth. As the material obtained here was a waste product of surgeries, indicated for medical reasons affecting different age groups: Cortical bone material is derived during wisdom teeth removal, which is typical for patients around 20 years of age. Cortical-cancellous bone chips are obtained during implantation surgery, which occurs throughout all ages.

Unlike outgrowth time, outgrowth success was comparable in the cortical bone chip group compared to the cortical-cancellous bone chip group and thus, seems to be independent of by age. This is in line with our findings for mesenchymal stem cells and those of others, but in contrast to the results of Chung and colleagues who showed that in vitro outgrowth of iliac crest bone-derived cells was more successful using material of young donors $[35,48,49]$. These contrary results might be explained with the different embryonic origin of the investigated bone chip sources. Iliac crest bone-derived cells are of mesenchymal origin, developing form the pharyngeal arches, whereas cells of the mandibular symphysis bone are ectomesenchymal, derived from the somites [6].

The capacity of BDSCs to differentiate towards the osteogenic lineage was further independent from the jawbone section the bone chips were collected from. This is in agreement with Chiriac and coworkers who found no significant differences in the characteristics of the first adherent cells with respect to the patient age and donor site [36]. Similar observations were made in the study of Kotte and colleagues [49]. 
The microbiological analysis showed that all collected bone chip samples had viable microorganisms. This was expected, since the oral cavity possesses the highest density of microorganisms after the colon [50]. Among all identified bacterial species gram-positive cocci have been shown to be most prominent. This correlates with the study by Young and colleagues [23]. Here, for the first time we show that the composition of microbes and their requirements for oxygen does not differ between outgrown and not outgrown stem cells from bone chip samples. Under standard cell culture conditions with antibioticsupplemented medium there were no differences in terms of quality and osteogenic potential of the BDSCs. It must be noted, that the conducted microbiological investigations were limited to the recognition of gram-positive or gram-negative cocci, aerobic and anaerobic microorganisms. Not all possible occurring species in the oral cavity, excluding pathogenic bacteria, rod-shaped gram-negative bacteria, yeasts and fungi, were detected due to test limitations. Also the API test is limited to the organism selected on the strips. A detailed analysis of the microorganisms using e.g., sequencing the DNA, performing genomic analysis on the 16S-RNA or Maldi-TOF would shed more light onto the microbiological composition found in the oral cavity. However, a pure culture would be the basis for a detailed identification without improving the information needed to judge isolation of stem cells and their possible use for bone grafts and thus, was not conducted herein.

Pre-surgical treatment of patients with Clindamycin significantly increased the outgrowth probability of the collected bone chips. In the cortical-cancellous bone chip group with antibiotic pretreatment the cells grew out significantly slower than those of the corresponding cortical-cancellous bone chip group without pre-operative antibiotic treatment. With regard to the cortical bone chip groups such a difference in the outgrowth time could not be observed. Duewelhenke and colleagues noticed an inhibitory effect of Clindamycin on the proliferation and metabolic activity of human osteoblasts in vitro [51]. This might also explain the increased outgrowth time and outgrowth probability of cortical compared to cortical-cancellous bone chips with antibiotic pre-treatment because Clindamycin can accumulate to higher amounts in the better blood-supplied trabecular bone than in compact bone. There are several references related to the quality of bone chips obtained from patients with antibiotic treatment prior to oral surgery [34,52-54]. Blay and coworkers evaluated the bacterial load of bone chips obtained from bone drilling [34]. The patients included in their study received prophylactic Amoxicillin-medication before the surgical procedure. The article is reviewing the clinical behavior of the collected autologous bone graft without having a non-antibiotic control group, which represents a major weak point of their study. It should be pointed out, that in order to reduce the bacterial contamination of the cortical bone chips collected during wisdom tooth removal, only completely impacted teeth were included in our study. This was not the case for the study published by Lambrecht and colleagues [52]. Antibiotic prophylaxis was shown previously to have a positive effect regarding the success of the implantation process in general [31,32]. Since it is not possible to obtain oral grafting material without bacterial contamination, a pre-surgical antibiotic treatment seems to be recommendable $[27,28,34,38,53,54]$. The cytotoxic or cytostatic effect of Clindamycin on primary human osteoblasts observed by Duewelhenke and coworkers might be reduced by choosing an alternative antibiotic, e.g., Ciprofloxacin. Beyond this, using antibiotic-supplemented bone grafts or rinsing the bone chips with a solution of antibiotics must be considered carefully $[27,28,55,56]$. Isefuku and colleagues reported that high concentration of Gentamicin inhibited proliferation of osteoblast-like cells in vitro while Rifampicin was shown to be harmful on osteoblasts and bone tissue $[57,58]$. Other studies investigating the effect of three antimicrobials showed also cytotoxicity on gingival MSCs [59]. In conclusion, high local antibiotic doses should be avoided and further investigations to define the best antibiotic, or combination of antibiotics, in in combination of utilizing stem cells for bone built-up in implantation are required.

Taken together, stem cells isolated from the medical waste of various dental tissues can be differentiated into multiple cell types. They can also be used to generate cell lines and iPSCs for long-term in vitro research [12]. In clinical studies the stability of dental implants 
using pre-osteoblasts from autogenic MSCs or xenogeneic grafts showed promising results. Riecke and colleagues evaluated the effect of transplantation of precultured preosteoblasts for experimental sinus floor augmentation on primary dental implant stability in comparison with conventional augmentation procedures in rabbits and revealed an enhanced primary stability of implants with experimental maxillary sinus floor augmentation with precultured osteoblast precursor cells from autogenic stems cells [60]. Lima et al. focused on volumetric stability of autologous and xenogeneic block grafts and primary stability of implants in maxillary grafted areas. They showed that xenogeneic block grafts are a suitable alternative to reconstruct horizontal defects in the alveolar ridge that had undergone extensive resorption [61]. Next to clinician's skills and surgery methods on the implant site preparation, which may also have an impact on the stability of implants, the use of different scaffold materials is steadily emerging and shows improving cell adhesion, growth and differentiation [62-64]. Thus, the question arises which bone chips are best for these investigations and consecutive treatments. With respect to the outgrowth time point of ectomesenchymal stem cells, cortical-cancellous bone chips are superior compared to those of cortical sources. Yet, cortical bone chips showed a comparable osteogenic differentiation potential and are known to be more stable against resorption under clinical conditions. Pre-operative antibiotic treatment of patients reduced the microbial contamination of the collected bone chip material without influencing its viability and increased the outgrowth success. Taken together, particulate and filtered mandibular bone chips are a useful grafting material in dental implantology.

Author Contributions: Conceptualization, E.T. and P.B.; methodology, P.B.; formal analysis, C.O.; investigation, P.B., C.K. and A.P.; resources, M.W.; writing—original draft preparation, P.B.; writingreview and editing, E.T.; visualization, P.B.; supervision, E.T.; project administration, E.T.; funding acquisition, E.T. All authors have read and agreed to the published version of the manuscript.

Funding: This research was funded by AdiPaD, BMBF-AiF, FKZ: 1720X06; Geräteprogramm, Fachhochschulen 2008 and 2009; HybridKEM, FKZ: 13FH569IX6.

Institutional Review Board Statement: The study was conducted according to the guidelines of the Declaration of Helsinki. The study protocol was accepted by the Ethics Committee of the University of Bonn (reference number 209/04). All patients gave their informed consent before taking part in the study.

Informed Consent Statement: Written informed consent had been obtained from the patient(s) to publish this paper.

Conflicts of Interest: The authors declare no conflict of interest.

\section{References}

1. Nefussi, J.R. Biology and physiology of the implant bone site. In Bone Augmentation in Oral Implantology; Khoury, F., Antoun, H., Missika, P., Eds.; Quintessence Publishing Co., Ltd.: Hanover Park, IL, USA, 2007; pp. 1-27.

2. Schlegel, K.A.; Fichtner, G.; Schultze-Mosgau, S.; Wiltfang, J. Histologic findings in sinus augmentation with autogenous bone chips versus a bovine bone substitute. Int. J. Oral Maxillofac. Implant. 2003, 18, 53-58.

3. Miron, R.J.; Hedbom, E.; Saulacic, N.; Zhang, Y.; Sculean, A.; Bosshardt, D.D.; Buser, D. Osteogenic potential of autogenous bone grafts harvested with four different surgical techniques. J. Dent. Res. 2011, 90, 1428-1433. [CrossRef] [PubMed]

4. Zippel, N.; Schulze, M.; Tobiasch, E. Biomaterials and mesenchymal stem cells for regenerative medicine. Recent Pat. Biotechnol. 2010, 4, 1-22. [CrossRef] [PubMed]

5. Schulze, M.; Tobiasch, E. Artificial scaffolds and mesenchymal stem cells for hard tissues. Adv. Biochem. Eng. Biotechnol. 2012, 126, 153-194.

6. Koole, R.; Bosker, H.; van der Dussen, F.N. Late secondary autogenous bone grafting in cleft patients comparing mandibular (ectomesenchymal) and iliac crest (mesenchymal) grafts. J. Cranio-Maxillo-Facial Surg. 1989, 17, 28-30. [CrossRef]

7. Sindet-Pedersen, S.; Enemark, H. Reconstruction of alveolar clefts with mandibular or iliac crest bone grafts: A comparative study. J. Oral Maxillofac. Surg. 1990, 48, 554-560. [CrossRef]

8. Chen, N.T.; Glowacki, J.; Bucky, L.P.; Hong, H.Z.; Kim, W.K.; Yaremchuk, M.J. The roles of revascularization and resorption on endurance of craniofacial onlay bone grafts in the rabbit. Plast. Reconstr. Surg. 1994, 93, 714-722. [CrossRef]

9. Girdler, N.M.; Hosseini, M. Orbital floor reconstruction with autogenous bone harvested from the mandibular lingual cortex. $B r$. J. Oral Maxillofac. Surg. 1992, 30, 36-38. [CrossRef] 
10. Raghoebar, G.M.; Meijndert, L.; Kalk, W.W.; Vissink, A. Morbidity of mandibular bone harvesting: A comparative study. Int. J. Oral Maxillofac. Implant. 2007, 22, 359-365.

11. Kainulainen, V.T.; Kainulainen, T.J.; Oikarinen, K.S.; Carmichael, R.P.; Sàndor, G.K.B. Performance of six bone collectors designed for dental implant surgery. Clin. Oral Implant. Res. 2006, 17, 282-287. [CrossRef]

12. Shoushrah, S.; Transfeld, J.; Tonk, C.; Büchner, D.; Witzleben, S.; Sieber, M.; Schulze, M.; Tobiasch, E. Sinking Our Teeth in Getting Dental Stem Cells to Clinics for Bone Regeneration. Int. J. Mol. Sci. 2021, 22, 6387. [CrossRef] [PubMed]

13. Smukler, H.; Capri, D.; Landi, L. Harvesting bone in the recipient sites for ridge augmentation. Int. J. Periodont. Restor. Dent. 2008, $28,411-419$.

14. Di Vito, A.; Giudice, A.; Chiarella, E.; Malara, N.; Bennardo, F.; Fortunato, L. In Vitro Long-Term Expansion and High Osteogenic Potential of Periodontal Ligament Stem Cells: More Than a Mirage. Cell Transpl. 2019, 1, 129-139. [CrossRef] [PubMed]

15. Ito, K.; Yamada, Y.; Nakamura, S.; Ueda, M. Osteogenic potential of effective bone engineering using dental pulp stem cells, bone marrow stem cells, and periosteal cells for osseointegration of dental implants. Int. J. Oral Maxillofac. Implant. 2011, 26, 947-954.

16. Rezai-Rad, M.; Bova, J.F.; Orooji, M.; Pepping, J.; Qureshi, A.; Del Piero, F.; Hayes, D.; Yao, S. Evaluation of bone regeneration potential of dental follicle stem cells for treatment of craniofacial defects. Cytotherapy 2015, 11, 1572-1581. [CrossRef]

17. Jin, Q.; Yuan, K.; Lin, W.; Niu, C.; Ma, R.; Huang, Z. Comparative characterization of mesenchymal stem cells from human dental pulp and adipose tissue for bone regeneration potential. Artif. Cells Nanomed. Biotechnol. 2019, 47, 1577-1584. [CrossRef]

18. Lloyd, B.; Tee, B.C.; Headley, C.; Emam, H.; Mallery, S.; Sun, Z. Similarities and differences between porcine mandibular and limb bone marrow mesenchymal stem cells. Arch. Oral Biol. 2017, 77, 1-11. [CrossRef]

19. Lee, D.J.; Kwon, J.; Current, L.; Yoon, K.; Zalal, R.; Hu, X.; Xue, P.; Ko, C.C. Osteogenic potential of mesenchymal stem cells from rat mandible to regenerate critical sized calvarial defect. J. Tissue Eng. 2019, 10, 2041731419830427. [CrossRef]

20. Li, C.; Wang, F.; Zhang, R.; Qiao, P.; Liu, H. Comparison of Proliferation and Osteogenic Differentiation Potential of Rat Mandibular and Femoral Bone Marrow Mesenchymal Stem Cells In Vitro. Stem Cells Dev. 2020, 29, 728-736. [CrossRef]

21. Groeneveldt, L.C.; Herpelinck, T.; Maréchal, M.; Politis, C.; van IJcken, W.F.J.; Huylebroeck, D.; Geris, L.; Mulugeta, E.; Luyten, F.P. The Bone-Forming Properties of Periosteum-Derived Cells Differ Between Harvest Sites. Front. Cell Dev. Biol. 2020, 8, 1-17. [CrossRef]

22. Hendrijantini, N.; Kusumaningsih, T.; Rostiny, R.; Mulawardhana, P.; Danudiningrat, C.P.; Rantam, F.A. A potential therapy of human umbilical cord mesenchymal stem cells for bone regeneration on osteoporotic mandibular bone. Eur. J. Dent. 2018, 12, 358-362. [CrossRef] [PubMed]

23. Young, M.P.J.; Korachi, M.; Carter, D.H.; Worthington, H.; Drucker, D.B. Microbial analysis of bone collected during implant surgery: A clinical and laboratory study. Clin. Oral Implant. Res. 2001, 12, 95-103. [CrossRef] [PubMed]

24. Young, M.P.J.; Korachi, M.; Carter, D.H.; Worthington, H.V.; McCord, J.F.; Drucker, D.B. The effects of an immediately pre-surgical chlorhexidine oral rinse on the bacterial contaminants of bone debris collected during dental implant surgery. Clin. Oral Implant. Res. 2002, 13, 20-29. [CrossRef] [PubMed]

25. Kuttenberger, J.J.; Hardt, N.; Rutz, T.; Pfyffer, G.E. Mit Knochenkollektor bei dentaler Implantation gewonnenes Knochenmaterial. Mikrobiologische Analyse. Mund-Kiefer-Und Gesichtschirurgie 2005, 9, 18-23. [CrossRef] [PubMed]

26. Kürkçü, M.; Öz, I.A.; Köksal, F.; Benlidayi, M.E.; Günesli, A. Microbial analysis of the autogenous bone collected by bone filter during oral surgery: A clinical study. J. Oral Maxillofac. Surg. 2005, 63, 1593-1598. [CrossRef]

27. Sivolella, S.; Berengo, M.; Scarin, M.; Mella, F.; Martinelli, F. Autogenous particulate bone collected with a piezo-electric surgical device and bone trap: A microbiological and histomorphometric study. Arch. Oral Biol. 2006, 51, 883-891. [CrossRef]

28. Etcheson, A.W.; Miley, D.D.; Gillespie, M.J. Osseous coagulum collected in bone traps: Potential for bacterial contamination and methods for decontamination. J. Oral Implantol. 2007, 33, 109-115. [CrossRef]

29. Dent, C.D.; Olson, J.W.; Farish, S.E.; Bellome, J.; Casino, A.J.; Morris, H.F.; Ochi, S. The influence of preoperative antibiotics on success of endosseous implants up to and including stage II surgery: A study of 2641 implants. J. Oral Maxillofac. Surg. 1997, 55, 19-24. [CrossRef]

30. Abu-Ta'a, M.; Quirynen, M.; Teughels, W.; van Steenberghe, D. Asepsis during periodontal surgery involving oral implants and the usefulness of peri-operative antibiotics: A prospective, randomized, controlled clinical trial. J. Clin. Periodontol. 2008, 35, 58-63. [CrossRef]

31. Al-Nawas, B.; Stein, K. Indication of a preoperative antibiotic prophylaxis for insertion of dental implants-A systematic review. J. Dent. Implantol. 2010, 26, 49-60.

32. Esposito, M.; Grusovin, M.G.; Loli, V.; Coulthard, P.; Worthington, H.V. Does antibiotic prophylaxis at implant placement decrease early implant failures? A Cochrane systematic review. Eur. J. Oral Implantol. 2010, 3, 101-110. [PubMed]

33. Eicker, L.A.; Tomakidi, P.; Haessler, D.; Neugebauer, J.; Zöller, J.E. Die Vitalität von gefilterten Knochenspänen zum präimplantologischen Knochenaufbau-Histochemische Untersuchungen und klinische Erfahrungen. Zeitschrift für Zahnärztliche Implantologie 2002, 18, 93-100.

34. Blay, A.; Tunchel, S.; Sendyk, W.R. Viability of autogenous bone grafts obtained by using bone collectors: Histological and microbiological study. Pesquisa Odontológica Brasileira 2003, 17, 234-240. [CrossRef] [PubMed]

35. Gruber, R.; Baron, M.; Busenlechner, D.; Kandler, B.; Fuerst, G.; Watzek, G. Proliferation and osteogenic differentiation of cells from cortical bone cylinders, bone particles from mill, and drilling dust. J. Oral Maxillofac. Surg. 2005, 63, 238-243. [CrossRef] 
36. Chiriac, G.; Herten, M.; Schwarz, F.; Rothamel, D.; Becker, J. Autogenous bone chips: Influence of a new piezoelectric device (Piezosurgery ${ }^{\circledR}$ ) on chip morphology, cell viability and differentiation. J. Clin. Periodontol. 2005, 32, 994-999. [CrossRef]

37. Zhang, Y.; Khan, D.; Delling, J.; Tobiasch, E. Mechanisms underlying the osteo- and adipo-differentiation of human mesenchymal stem cells. Sci. World J. 2012, 2012, 793823. [CrossRef]

38. Graziani, F.; Cei, S.; Ivanovski, S.; La Ferla, F.; Gabriele, M.A. systematic review of the effectiveness of bone collectors. Int. J. Oral Maxillofac. Implant. 2007, 22, 729-735.

39. Haessler, D.; Zöller, J.; Vizethum, F. Autogene Knochentransplantation mit Hilfe eines Spankollektors-Eine Methodenbeschreibung. Implantologie 1995, 4, 315-322.

40. Rasmusson, L. Knochenaufbau bei lokalen Alveolarkammdefekten. Dent. Implantol. Parodontol. 2002, 6, $24-26$.

41. Dominici, M.; Le Blanc, K.; Mueller, I.; Slaper-Cortenbach, I.; Marini, F.; Krause, D.; Deans, R.; Keating, A.; Prockop, D.; Horwitz, E. Minimal criteria for defining multipotent mesenchymal stromal cells. The International Society for Cellular Therapy position statement. Cytotherapy 2006, 8, 315-317. [CrossRef]

42. Haddouti, E.M.; Skroch, M.; Zippel, N.; Müller, C.; Birova, B.; Pansky, A.; Kleinfeld, C.; Winter, M.; Tobiasch, E. Human dental follicle precursor cells of wisdom teeth: Isolation and differentiation towards osteoblasts for implants with and without scaffolds. Mater. Sci. Eng. Technol. 2009, 40, 732-737. [CrossRef]

43. Khan, D.; Kleinfeld, C.; Winter, M.; Tobiasch, E. Oral tissues as source for bone regeneration in dental implantology. In Tissue Regeneration-From Basic Biology to Clinical Application; Davies, J., Ed.; IntechOpen: London, UK, 2012; pp. 325-338.

44. Zippel, N.; Limbach, C.A.; Ratajski, N.; Urban, C.; Luparello, C.; Pansky, A.; Kassack, M.U.; Tobiasch, E. Purinergic receptors influence the differentiation of human mesenchymal stem cells. Stem Cells Dev. 2012, 21, 884-900. [CrossRef] [PubMed]

45. Tobiasch, E. Differentiation potential of adult human mesenchymal stem cells. In Stem Cell Engineering; Artmann, G.M., Hescheler, J., Minger, S., Eds.; Springer: Berlin/Heidelberg, Germany, 2010.

46. Springer, I.N.G.; Terheyden, H.; Geiß, S.; Härle, F.; Hedderich, J.; Açil, Y. Particulated bone grafts-effectiveness of bone cell supply. Clin. Oral Implant. Res. 2004, 15, 205-212. [CrossRef] [PubMed]

47. Longo, A.; Librizzi, M.; Naselli, F.; Caradonna, F.; Tobiasch, E.; Luparello, C. PTHrP in differentiating human mesenchymal stem cells: Transcript isoform expression, promoter methylation, and protein accumulation. Biochimie 2013, 95, 1888-1896. [CrossRef]

48. Chung, S.M.; Kim, E.-B.; Park, S.-Y.; Sung, M.C.; Youn, H.K.; Ahn, M.-W. Effect of bone marrow cell collection techniques and donor site locations on in-vitro growth of bone forming cells. Asian Spine J. 2008, 2, 59-63. [CrossRef]

49. Kotte, B.M. Optimierung der Wachstumsbedingungen Humaner Osteoblasten In Vitro. Ph.D. Thesis, Medizinische Fakultät der Universität Leipzig, Leipzig, Germany, 2005.

50. Evaldson, G.; Heimdahl, A.; Kager, L.; Nord, C.E. The normal human anaerobic microflora. Scand. J. Infect. Dis. Suppl. 1982, 35, 9-15.

51. Duewelhenke, N.; Krut, O.; Eysel, P. Influence on mitochondria and cytotoxicity of different antibiotics administered in high concentrations on primary human osteoblasts and cell lines. Antimicrob. Agents Chemother. 2007, 51, 54-63. [CrossRef]

52. Lambrecht, J.T.; Glaser, B.; Meyer, J. Bacterial contamination of filtered intraoral bone chips. Int. J. Oral Maxillofac. Surg. 2006, 35, 996-1000. [CrossRef]

53. Tezulas, E.; Dilek, O.C. Decontamination of autogenous bone grafts collected from dental implant sites via osteotomy: A review. Oral Surg. Oral Med. Oral Pathol. Oral Radiol. Endod. 2008, 106, 679-684. [CrossRef]

54. Takamoto, M.; Takechi, M.; Ohta, K.; Ninomiya, Y.; Ono, S.; Shigeishi, H.; Tada, M.; Kamata, N. Risk of bacterial contamination of bone harvesting devices used for autogenous bone graft in implant surgery. Head Face Med. 2013, 9, 3. [CrossRef]

55. Petri, W.H., 3rd; Schaberg, S.J. The effects of antibiotic-supplemented bone allografts on contaminated, partially avulsive fractures of the canine ulna. J. Oral Maxillofac. Surg. 1984, 42, 699-704. [CrossRef]

56. Petri, W.H., 3rd; Wilson, T.M. Clinical evaluation of antibiotic-supplemented bone allograft. J. Oral Maxillofac. Surg. 1993, 51, 982-985. [CrossRef]

57. Isefuku, S.; Joyner, C.J.; Simpson, A.H. Toxic effect of rifampicin on human osteoblast-like cells. J. Orthop. Res. 2001, 19, 950-954. [CrossRef]

58. Isefuku, S.; Joyner, C.J.; Simpson, A.H. Gentamycin may have an adverse effect on osteogenesis. J. Orthop. Trauma 2003, 17, 212-216. [CrossRef] [PubMed]

59. Lupșe, I.; Pall, E.; Tudoran, L.B.; Bulboacă, A.E.; Ciurea, A.; Micu, I.C.; Roman, A.; Delean, A.G.; Muntean, A.; Soancă, A Cytotoxic Effects on Gingival Mesenchymal Stromal Cells and Root Surface Modifications Induced by Some Local Antimicrobial Products Used in Periodontitis Treatment. Materials 2021, 14, 5049. [CrossRef] [PubMed]

60. Riecke, B.; Heiland, M.; Hothan, A.; Morlock, M.; Amling, M.; Blake, F.A. Primary implant stability after maxillary sinus augmentation with autogenous mesenchymal stem cells: A biomechanical evaluation in rabbits. Clin. Oral Implant. Res. 2011, 11, 1242-1246. [CrossRef]

61. Lima, R.G.; Lima, T.G.; Francischone, C.E.; Turssi, C.; Souza Picorelli Assis, N.M.; Sotto-Maior, B.S. Bone Volume Dynamics and Implant Placement Torque in Horizontal Bone Defects Reconstructed with Autologous or Xenogeneic Block Bone: A Randomized, Controlled, Split-Mouth, Prospective Clinical Trial. Int. J. Oral Maxillofac. Implant. 2018, 33, 888-894. [CrossRef]

62. Giudice, A.; Bennardo, F.; Antonelli, A.; Barone, S.; Wagner, F.; Fortunato, L.; Traxler, H. Influence of clinician's skill on primary implant stability with conventional and piezoelectric preparation techniques: An ex-vivo study. J. Biol. Regul. Homeost. Agents 2020, 2, 739-745. 
63. Ding, S.J.; Chu, Y.H.; Chen, P.T. Mechanical Biocompatibility, Osteogenic Activity, and Antibacterial Efficacy of Calcium SilicateZirconia Biocomposites. ACS Omega 2021, 10, 7106-7118. [CrossRef]

64. Lu, X.; Chen, Y.; Mao, P.; Chen, L.; Han, X.; Sun, F. Nanoparticle Shaped Titanium Promotes Osteogenic Differentiation of Bone Mesenchymal Stem Cells Through Integrin/Integrin Linked Kinase/Glycogen Synthase Kinase-3 $\beta$ Axis. J. Biomed. Nanotechnol. 2020, 8, 1267-1275. [CrossRef] 